Antunes, R.C.; Tôrres, A.J.F.; Scalco, R.F. Análise da proposta do Plano de Manejo para estruturação do Parque Estadual do Biribiri. Revista Brasileira de Ecoturismo, São Paulo, v.5, n.2, mai/ago-2012, pp.245-262.

\title{
Análise da proposta do Plano de Manejo para estruturação do Parque Estadual do Biribiri ${ }^{1}$
}

\author{
Analysis of the Management Plan proposal to organization the \\ Biribiri State Natural Park (MG), Brazil \\ Raquel Campos Antunes, Álvaro José Ferreira Tôrres, \\ Raquel Faria Scalco
}

\begin{abstract}
RESUMO
A presente pesquisa foi desenvolvida com o objetivo de analisar a proposta do Plano de Manejo do Parque Estadual do Biribiri - PEBI, localizado em Diamantina - MG, no que se refere à implantação de estruturas físicas de apoio à visitação e gestão do Parque. Para tanto, foram utilizados os seguintes procedimentos metodológicos: pesquisa bibliográfica, pesquisa de gabinete, análise do plano de manejo e entrevista semiestruturada com atores que se mostraram relevantes para a realização deste estudo. Por meio do desenvolvimento destas etapas, foi possível entender a necessidade de atualização, revisão e implementação das estruturas propostas no Plano de Manejo do PEBI para oferecer condições mínimas para sua visitação. Percebeu-se que a presença de tais estruturas poderia contribuir de maneira positiva, pois possibilitariam um maior controle e segurança ao Parque, aumento da conservação do meio ambiente, além da meIhoria da qualidade da visitação turística da área. Constatou-se, ainda, que a implantação de tais estruturas contribuiria para minimizar impactos ambientais negativos e para o desenvolvimento turístico, socioeconômico e ambiental de Diamantina e região.
\end{abstract}

PALAVRAS-CHAVE: Unidade de Conservação; Plano de Manejo; Estruturas Físicas.

\section{ABSTRACT}

The aim of this research were analyzing the proposal of the Management Plan of Natural Park of Biribiri State (PEBI), in Diamantina (MG, Brazil), and the implementation of infrastructure to support visitors and the park management. For this purpose, we used the methodological proceedings: literature and cabinet research, analysis of the management plan and semi-structured interviews with relevant actors to this study. With these steps we could understand the necessity for updating, review and implementation of the proposed structures in the Management Plan of the PEBI to offer the minimum conditions for their visitation. These structures could be positive because they permit a better control and security to the park, increasing the environment conservation and an improving of the quality of tourist visitation in this area. It was found also that the implementation of such structures would help the touristic, socioeconomic and environmental development and minimize environmental impacts in Diamantina and region.

KEYWORDS: Protected Areas; Management Plan; Physical Structures. 


\section{Introdução}

Diamantina, cidade inserida no Vale do Jequitinhonha, ao norte de Minas Gerais, distante $292 \mathrm{Km}$ da capital Belo Horizonte, é reconhecida como Patrimônio Cultural da Humanidade pela UNESCO. É uma cidade colonial que apresenta um cenário formado pelos belos casarões e também pela paisagem da Serra do Espinhaço.

Intitulada como um dos 65 destinos indutores do turismo, o que eleva a cidade diante da demanda turística, Diamantina ainda conta com o legado de grandes personalidades como a escrava Chica da Silva e o ex-presidente Juscelino Kubitschek, que se tornaram referências para muitas pessoas que buscam conhecer a história do município. Com rico acervo histórico-colonial e inúmeros atrativos naturais, o município proporciona a seus visitantes a oportunidade de vivenciar momentos de cultura, diversão e lazer.

Principiante nas atividades turísticas em meio natural, o ecoturismo diamantinense se mostra potencialmente muito forte. A cidade se encontra em localização privilegiada, em um dos mais belos trechos da Estrada Real, na Serra do Espinhaço, possuindo vários atrativos naturais, ricos em beleza cênica, como as diversas cachoeiras, grutas, serras e trilhas presentes na região.Assim, o espaço de Diamantina propicia unir a forte identidade cultural ao contato direto com a natureza do local.

A marcante presença de Unidades de Conservação (UCs) também faz de Diamantina um destino peculiar. Segundo o Instituto Estadual de Florestas - IEF (2011), a cidade está próxima a duas UCs Estaduais - Parque Estadual do Rio Preto e Parque Estadual Pico do Itambé - e abrange em seu território a APA das Águas Vertentes, o Parque Nacional das Sempre Vivas e o Parque Estadual do Biribiri - PEBI, que é o objeto de estudo da presente pesquisa.

Criado em 22 de Setembro de 1998, pelo Decreto ํㅜ 39.909, o Parque Estadual do Biribiri tem área aproximadamente de 16.998 hectares, O PEBI abriga diversas nascentes e cursos d'água que, junto aos rios de leitos de pedras, formam as cachoeiras do Parque, como a Sentinela (Figura 1) e Cristais (Figura 2), duas das de maiores beleza natural da região onde está inserido (complexo da Serra do Espinhaço - Figura 3, adiante)(IEF, 2011).

O PEBI proporciona ao visitante, a oportunidade de praticar atividades de contemplação da paisagem, de pinturas rupestres, da fauna e flora local, realização de trilhas, assim como desfrutar das diversas cachoeiras, que fazem do Parque um importante atrativo natural.

Esta é uma Unidade de Conservação de Proteção Integral, grupo de UCs que têm como objetivo básico preservar a natureza, admitindo apenas o uso indireto dos recursos naturais (BRASIL, Lei 9.985, art.7º $§ 1^{\circ}, 2000$ ). 


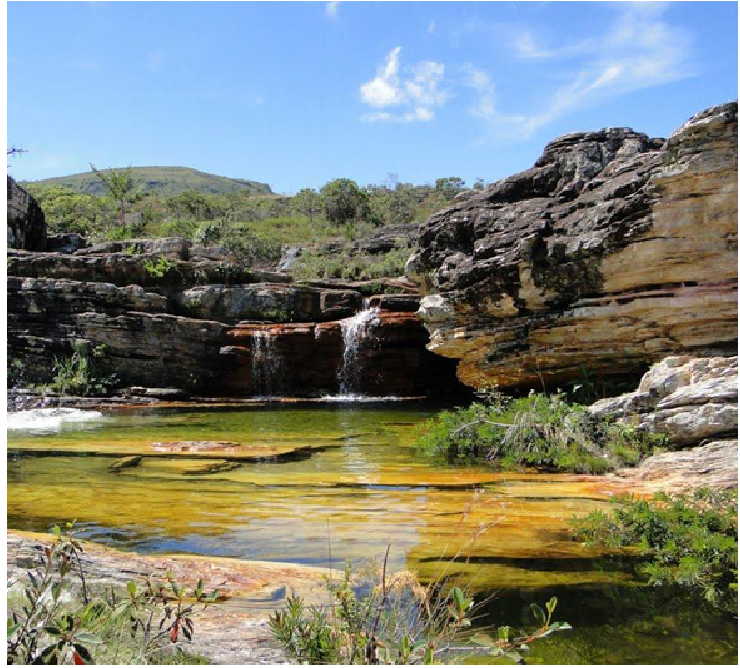

Figura 1: Cachoeira Sentinela. Foto: Patrícia Carocci, 2010. Figure 2: Sentinela Waterfall. Photo: Patrícia Carocci, 2010.

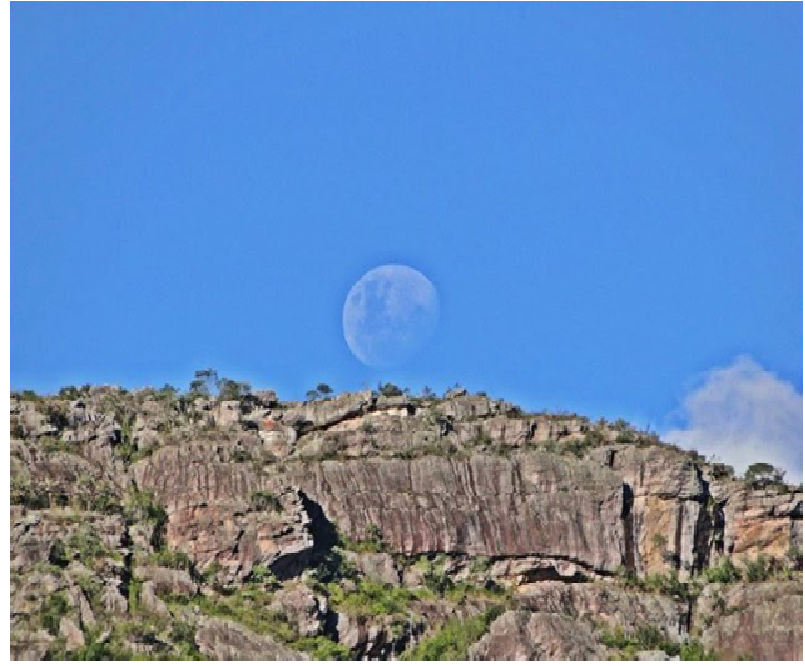

Figura 2: Serra dos Cristais. Foto: Patrícia Carocci, 2010. Figure 3: Cristais' Mountain. Photo: Patrícia Carocci, 2010.

Este estudo buscou analisar a proposta do Plano de Manejo do PEBI para a implantação de estruturas físicas de apoio à visitação e gestão do Parque Estadual do Biribiri, a partir das opiniões dos diversos atores que se mostraram relevantes para o desenvolvimento desta pesquisa, avaliando a viabilidade da inserção de tais estruturas no local. Para tanto, foi necessário compreender a importância da presença desses equipamentos que possivelmente contribuiriam para minimizar os impactos negativos em ambientes naturais, e, consequentemente, com a proposta de desenvolvimento do ecoturismo no local.

Como referência, foi utilizado como fonte de consulta sobre as estruturas físicas a serem implantadas no Parque, o seu Plano de Manejo, elaborado pela empresa STCP Engenharia de Projetos LTDA, em 2004, bem como a realização de entrevistas semiestruturadas, fundamentais para as análises aqui apresentadas.

\section{Turismo e Unidades de Conservação}

O Sistema Nacional de Unidades de Conservação - SNUC (BRASIL, Lei no 9.985, Art.2, 2000) define Plano de Manejo como:

Documento técnico mediante o qual, com fundamento nos objetivos gerais de uma unidade de conservação, se estabelece o seu zoneamento e as normas que devem presidir o uso da área e o manejo dos recursos naturais, inclusive a implantação das estruturas físicas e necessárias à gestão da unidade. 
Entende-se, sobretudo, que a prática de atividades turísticas em meio natural requer demasiado cuidado, buscando preservar os recursos e minimizar impactos negativos ao ambiente. Portanto, o planejamento do ecoturismo se faz tão importante quanto a sua prática.

De acordo com Ruschmann (2010), é notável que a realização do turismo em ambientes naturais, que são extremamente sensíveis, tem se tornado uma atividade de grande procura, impulsionada pelo desejo de vivenciar a natureza e fugir do cotidiano dos grandes centros urbanos. O aumento do fluxo de visitação nos ambientes naturais faz do planejamento, da presença de estruturas e da oferta de serviços turísticos, ferramentas essenciais para que o turismo seja desenvolvido de forma ordenada e menos impactante.

O Ecoturismo é um dos importantes segmentos da atividade turística, que atualmente vem ganhando cada vez mais espaço no mercado em função da procura por melhoria na qualidade de vida, que pode ser obtida por meio de práticas e experiências vivenciadas em meio natural.De acordo com o Ministério do Turismo - MTUR (2010, p.21):

[...] o ecoturismo pode ser entendido como as atividades turísticas baseadas na relação sustentável com a natureza e as comunidades receptoras, comprometidas com a conservação, a educação ambiental e o desenvolvimento socioeconômico.

Já segundo Goodwin (1966, apud NEIMAN, 2010, p.46):

O ecoturismo é o turismo de natureza, de baixo impacto, que contribui à manutenção de espécies e habitats diretamente, por meio de uma contribuição á conservação e ou indiretamente produzindo rendimentos para as comunidades locais, para que elas valorizem e, portanto, protejam suas áreas herdadas de vida selvagem como fonte de renda.

O ecoturismo é, então, uma atividade de lazer fundamentada no desenvolvimento sustentável, na conservação do ambiente, nas práticas educacionais e na relação harmoniosa entre a natureza, comunidade local e o visitante.

Promover a ideia de preservação do ambiente e incentivar a adoção de práticas ecologicamente corretas no dia-a-dia, e não somente durante a realização efetiva das viagens, é de grande importância para o turismo, visto que o meio ambiente é matéria-prima desta atividade, e, sendo assim, deve-se manter a conservação e o equilíbrio do meio.

Ressalta-se a importância de desenvolver o ecoturismo, atento às premissas básicas da atividade, a fim de proporcionar a educação e preservação ambiental, sen- 
sibilizar e envolver turistas e comunidade e trazer desenvolvimento social e econômico para o local.

\section{Importância da Presença de Estruturas Físicas em Unidades de Conservação}

A presença de estruturas físicas em Unidades de Conservação, sobretudo em Parques, é de fundamental importância para que haja apoio à visitação e gestão do espaço, pois estas direcionam as atividades decorrentes da visitação para locais mais adequados, implicando a minimização dos impactos negativos e maior conservação do meio ambiente. Esta estruturação também é imprescindível para ampliação de oportunidades para as comunidades do entorno, como forma de geração de emprego e renda.

Outra importante consideração é que a implantação de estruturas físicas nessas áreas contribui para o alcance dos objetivos de criação dessas UCs. Dentre os objetivos básicos dessa categoria estão a visitação pública voltada à educação ambiental, recreação e turismo ecológico, desenvolvimento de pesquisas científicas e conservação dos recursos naturais.

Assim, as estruturas físicas de apoio à visitação e gestão de Parques contribuem de forma determinante para a maior conservação dos recursos naturais e a redução dos impactos ambientais, o ordenamento do fluxo de visitação, influencia na satisfação do visitante, bem como em possibilidades de geração de renda para a comunidade.

Portanto, para a consolidação dos objetivos de uma UC, é essencial que as propostas abarcadas pelo Plano de Manejo da área sejam analisadas e de fato implementadas, propiciando melhores condições de uso do espaço, visando aliar a preservação do meio ambiente com o desenvolvimento responsável do ecoturismo.

\section{Materiais e Métodos}

O presente trabalho foi desenvolvido com a finalidade de analisar a proposta do Plano de Manejo do Parque Estadual do Biribiri, no que se refere à implantação de estruturas físicas de apoio à visitação e gestão do Parque,com base nas opiniões dos diversos atores que se mostraram relevantes para o desenvolvimento desta pesquisa.

A escolha do Parque Estadual do Biribiri como objeto de estudo ocorreu em função desta UC não possuir estruturas de apoio à visitação e gestão ainda implantadas e, também, pelo fato do Plano de Manejo do PEBI não ter sido implementado e tampouco atualizado, desde sua elaboração em 2004.

A metodologia utilizada para o desenvolvimento da pesquisa se baseou em pesquisas exploratórias e qualitativas, que consiste na caracterização do problema, assim como na coleta e análise de dados primários e secundários, buscando interpretar e detaIhar aspectos mais profundos do objeto de estudo.

O procedimento metodológico da presente pesquisa compreendeu, em um primeiro momento, pesquisas bibliográficas fundamentalmente nas áreas de Turismo e Meio Ambiente, Unidades de Conservação, Uso Público em Unidades de Conservação, Plano de Manejo, Ecoturismo, Legislação Ambiental, Impactos do Turismo em Ambientes Natu- 
rais, dentre outros temas. A Pesquisa Bibliográfica é aquela desenvolvida a partir de material já publicado para elaboração conceitual e definição de marcos teóricos (DENCKER, 1998).

Em sequência, foram feitas pesquisas documentais e pesquisas de gabinete junto aos órgãos de administração pública relacionados direta ou indiretamente com a gestão e conservação do Parque Estadual do Biribiri, para conhecer os atores-chaves que têm relação com a Unidade de Conservação e para coletar informações nas diversas instituições vinculadas ao PEBI. Para essa etapa, foram feitas análises de materiais, pesquisas e projetos anteriormente realizados pelo Instituto Estadual de Floresta (IEF), pela Prefeitura Municipal de Diamantina e pela Universidade Federal dos Vales do Jequitinhonha e Mucuri (UFVJM). "As fontes documentais podem ser documentos de primeira mão conservados em artigos e instituições públicas e privadas" (DENCKER, 1998, p.125).

As duas etapas acima descritas são importantes, segundo a OMT (apud DENCKER, 1998) a fim de garantir a evolução do processo do conhecimento.

Posteriormente, foi feita a análise da proposta de implantação de estruturas físicas do Plano de Manejo, no que se refere ao apoio à visitação e gestão do Parque.

Em seguida, foram realizadas entrevistas semiestruturadas, com atores que se mostraram relevantes para o desenvolvimento dessa pesquisa.

Segundo Dencker (2007, p.165) "a entrevista é uma comunicação oral entre duas ou mais pessoas, com grau de estruturação previamente definido, cuja finalidade é a obtenção de informações de pesquisa".

Foram feitas 09 entrevistas, no período de 05 de outubro de 2011 a 09 de novembro de 2011, com os seguintes atores: Gestor do PEBI, Guarda-Parque do PEBI; exfuncionário do Instituto Estadual de Florestas (IEF), funcionários do Instituto Biotrópicos, pesquisadores da área, representante da Secretaria Municipal de Cultura e Turismo (SECTUR) e representante da Comunidade do entorno do PEBI. Nestas entrevistas foram abordados temas que nortearam as discussões, como a atividade turística no PEBI; a importância da presença de estruturas físicas em Unidades de Conservação; a avaliação das propostas desse documento e sugestões de mudanças nas estruturas previstas no Plano de Manejo do Parque.

A partir da realização desta pesquisa, foi possível diagnosticar aspectos de fundamental importância, tanto para o Parque quanto para o cenário turístico, socioeconômico e ambiental do município e região. Esses aspectos serão analisados a seguir.

\section{Resultados e Discussões}

O presente estudo foi desenvolvido com o propósito de analisar o disposto no Plano de Manejo do Parque Estadual do Biribiri, no que tange a implantação de estruturas físicas de apoio à visitação e gestão da Unidade de Conservação. Para tanto, partiu-se de uma análise dos autores sobre o Plano de Manejo do PEBI e de outros documentos relevantes sobre o Parque, bem como a análise das entrevistas realizadas. Nestas entrevistas foram abordados temas que nortearam as discussões que serão apresentadas a seguir. 
O Plano de Manejo do PEBI apresenta algumas propostas em relação à implantação de estruturas físicas de apoio à visitação e gestão da Unidade de Conservação. Essas propostas estão sintetizadas na Tabela 1. Para melhor entendimento acerca da área do Parque, a Figura 3 apresenta o Mapa do Programa de Uso Público no Contexto de Zoneamento do Parque Estadual do Biribiri.

Tabela 1: Estruturas e localização propostas pelo Plano de Manejo do Parque Estadual do Biribiri. Table 1: Structures and location proposals by the Management Plan for the Biribiri State Natural Park.

\begin{tabular}{|c|c|}
\hline Estruturas & Dimensão e Localização no PEBI \\
\hline Centro Administrativo & 150 m², Zona de Uso Especial, Porção Sul \\
\hline Centro de Manutenção e Apoio ao Funcionário & $300 \mathrm{~m}^{2}$, Zona de Uso Especial, Porção Sul \\
\hline Casa do Funcionário & 96 m²$^{2}$ Zona de Uso Intensivo, Porção Sul \\
\hline Centro de Visitantes & 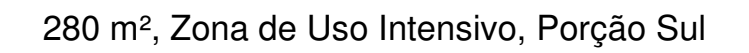 \\
\hline Portaria Principal & $\begin{array}{l}20 \mathrm{~m}^{2} \text {, Zona de Uso Intensivo, } \\
\text { Porção Sul }\end{array}$ \\
\hline $\begin{array}{c}\text { Núcleo de Apoio ao Uso Público com Primei- } \\
\text { ros Socorros }\end{array}$ & $\begin{array}{c}150 \mathrm{~m}^{2} \text {, Zona de Uso Intensivo, Cachoeira da } \\
\text { Sentinela }\end{array}$ \\
\hline Estacionamento & Cachoeira da Sentinela, Zona de Uso Intensivo \\
\hline $\begin{array}{c}\text { Guarita na Estrada Municipal Sentido Pinheiros- } \\
\text { Diamantina }\end{array}$ & $9 \mathrm{~m}^{2}$, Zona de Uso Especial \\
\hline Guarita na Vila do Biribiri & $9 \mathrm{~m}^{2}$, Zona de Uso Especial \\
\hline Guarita na Cachoeira Sentinela & $9 \mathrm{~m}^{2}$, Zona de Uso Intensivo \\
\hline Portaria em Mendanha & $\begin{array}{l}40 \mathrm{~m}^{2} \text {, Zona de Uso Especial, } \\
\text { Distrito de Mendanha }\end{array}$ \\
\hline Centro de Referência do Parque & Casa na Vila do Biribiri \\
\hline Base de Apoio ao Pesquisador & Indefinido \\
\hline $\begin{array}{c}\text { Sanitário e Estacionamento Próximo à Fazen- } \\
\text { da Duas Pontes }\end{array}$ & Zona de Uso Intensivo \\
\hline Portão na Entrada Pela Fazenda Duas Pontes & Zona de Uso Intensivo \\
\hline
\end{tabular}

Fonte: Adaptado de STCP Engenharia de Projetos LTDA., 2004).

Source: Adapted from STCP Engenharia de Projetos LTDA., 2004). 

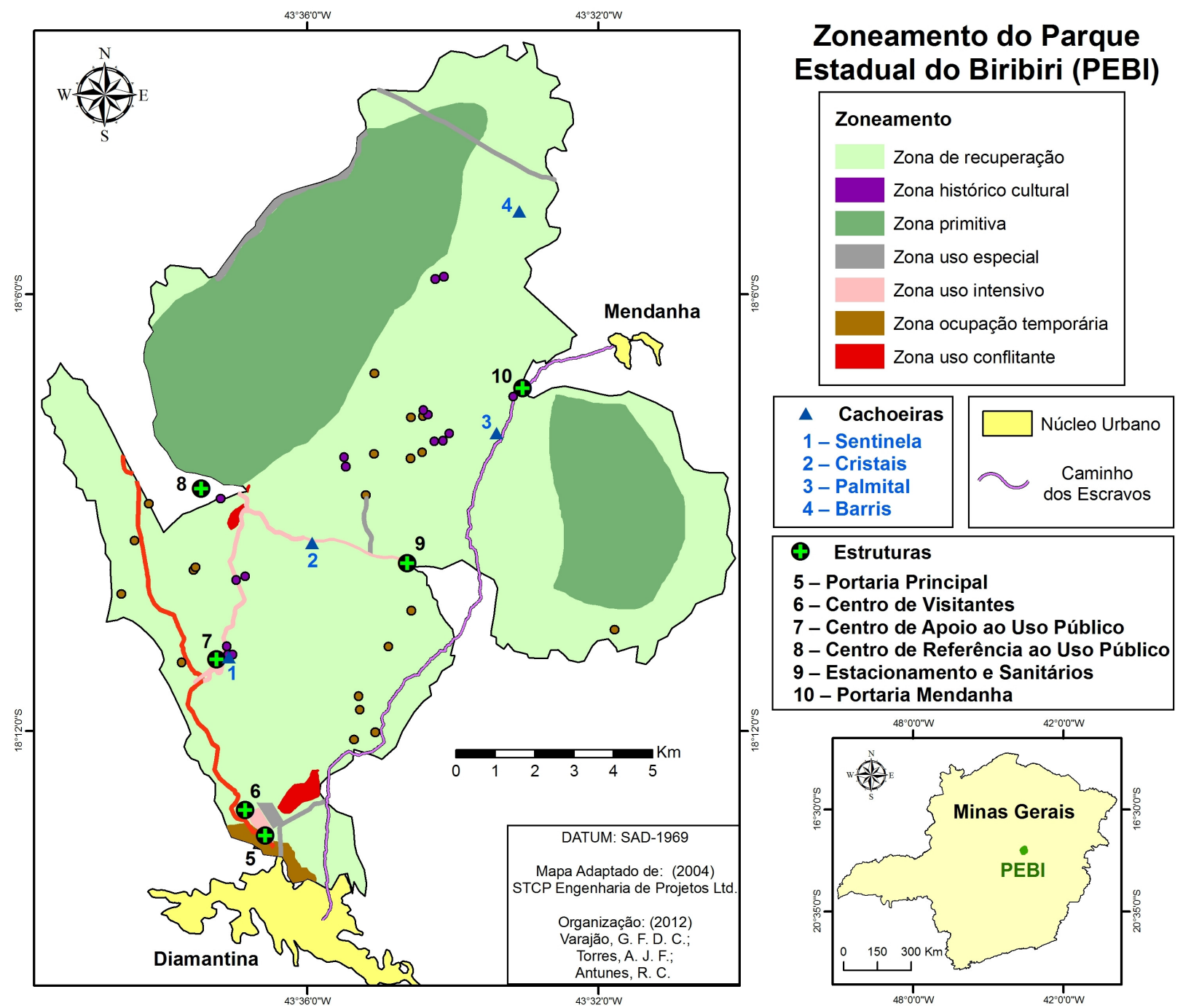

9 - Estacionamento e Sanitários 10 - Portaria Mendanha

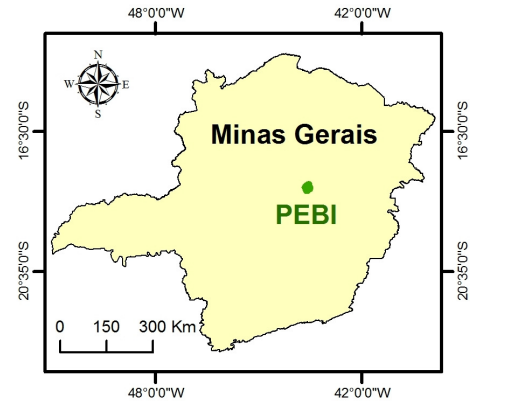

Figura 3: Mapa de Zoneamento do Parque Estadual do Biribiri (PEBI). Fonte: Plano de Manejo do Parque Estadual do Biribiri (Adaptado de: STCP Engenharia de Projetos Ltda, 2004).

Figure 3: Zoning Map of the Biribiri State Natural Park.. Source: Management Plan for the Biribiri State Natural Park ( Adapted from: STCP Engenharia de Projetos Ltda, 2004).

\section{A Atividade Turística no Parque Estadual do Biribiri}

A avaliação da atividade turística no Parque Estadual do Biribiri expôs que este é um atrativo turístico de Diamantina com grande fluxo de visitação, concentrada em determinadas áreas do Parque e em algumas épocas do ano, como carnaval e outros feriados nacionais.

De acordo com Silveira e Medaglia (2011), o Parque é o atrativo natural mais visitado em Diamantina e região. Ávila e Paula (2010) também constatam que o fluxo de visitação no Parque Estadual do Biribiri é intenso e contínuo e que há um aumento significativo de visitantes a cada ano (Figura 4). Estes dados reforçam a importância da 
implantação de estruturas físicas que possivelmente auxiliariam no controle do fluxo de visitação e na manutenção das atividades realizadas na área do Parque, como portarias, sanitários e estacionamentos.

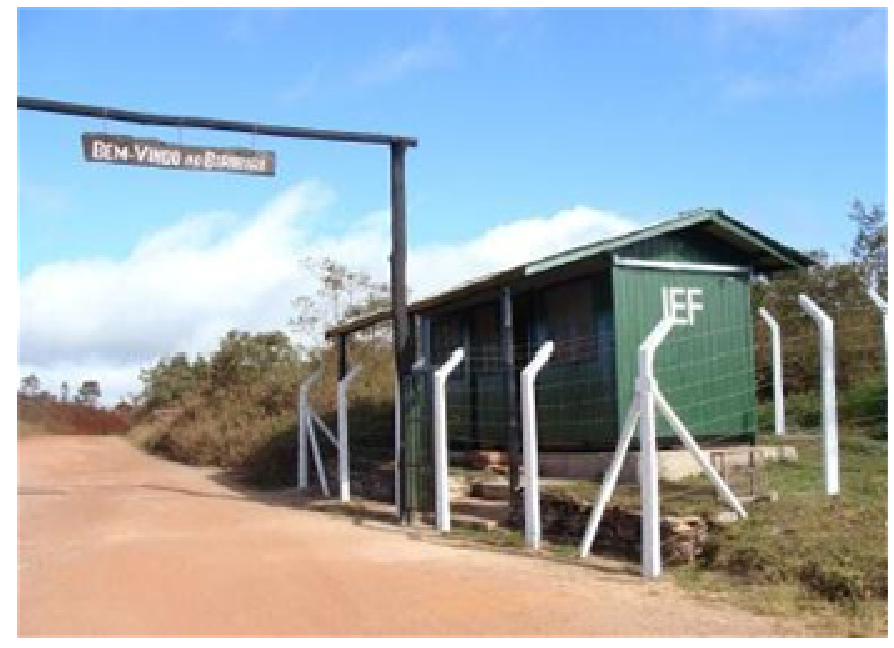

Figura 4: Número Total de Visitantes no Parque Estadual do Biribiri. Fonte: Ávila e Paula (2010). Figure 4: Total Number of Visitors in the Biribiri State Natural Park. Source: Ávila e Paula (2010).

Atualmente, o Parque Estadual do Biribiri, oferece condições mínimas para visitação, possuindo apenas as seguintes estruturas físicas: container-portaria (Figura 5), placas de sinalização, vias de acesso não pavimentadas e estacionamento na Cachoeira da Sentinela. Segundo Ávila e Paula (2010), "a instalação do Container-Portaria, na região sul do PEBI, foi o salto físico mais importante do parque desde sua criação".

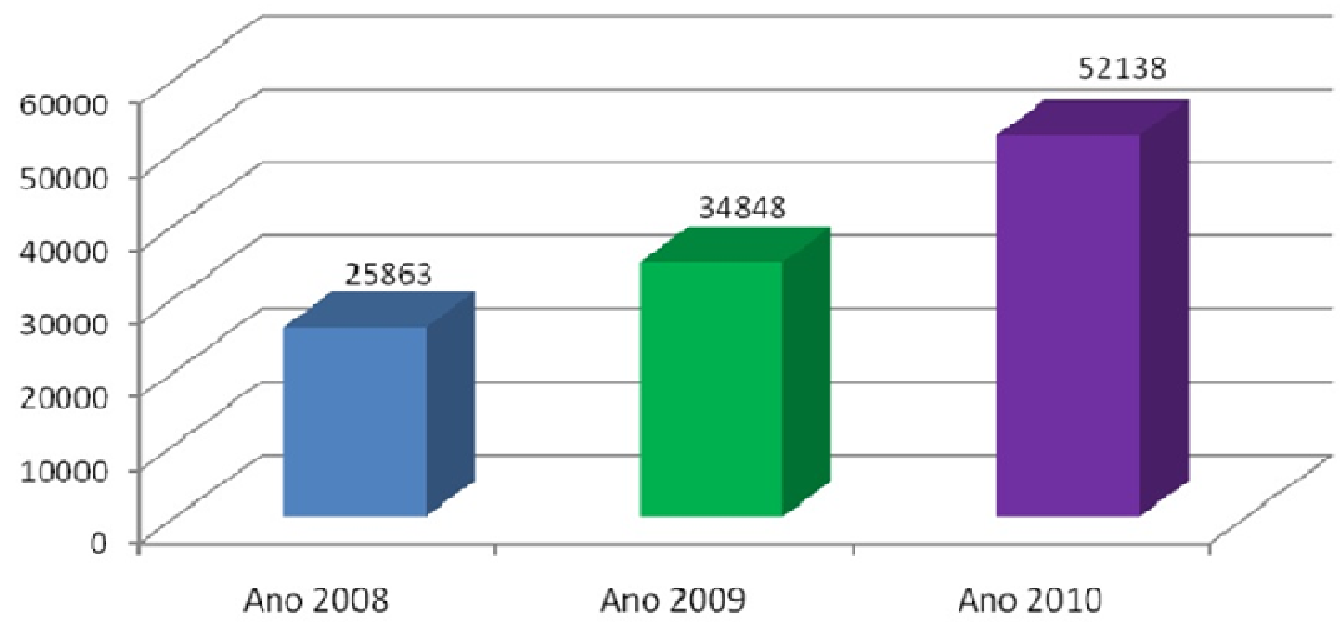

Figura 5: Container Portaria do Parque Estadual do Biribiri. Fonte: Ávila e Paula (2010). Figure 5: Container Ordinance of the Biribiri State Natural Park. Source: Ávila e Paula (2010). 
Um dos maiores entraves para o cumprimento dos objetivos de criação da UC e para a implantação de estruturas físicas no PEBI é a falta de regularização fundiária, que interfere no processo de implementação das propostas do Plano de Manejo. Isso dificulta o desenvolvimento do ecoturismo de forma responsável no Parque.

Atualmente,o Parque não se encontra oficialmente aberto à visitação, porém esta acontece de forma espontânea e sem controle, acarretando diversos impactos para o meio ambiente do PEBI. A falta de estrutura, segurança e monitoramento das atividades no Parque Estadual do Biribiri tornam o desenvolvimento do turismo na UC desordenado e altamente impactante, o que reitera a importância do ordenamento da atividade e da implantação de estruturas de apoio à visitação e gestão da Unidade de Conservação.

Em função da carência de estruturas turísticas, o Parque Estadual do Biribiri se torna vulnerável, aumentando assim a ocorrência de impactos negativos tanto para o meio ambiente quanto para a atividade turística e seus consumidores. Atualmente, são visíveis no PEBI alguns problemas, como por exemplo: a degradação de trilhas, a falta de controle de acesso ao Parque, a produção de resíduos em excesso, a poluição de cursos d'água e a falta de orientação sobre o comportamento dentro do Parque, o que pode provocar atitudes inadequadas pelos visitantes que prejudicam e alteram o meio ambiente.

Considerando que o PEBI é um importante atrativo para o turismo de Diamantina, capaz de influenciar no aumento do fluxo turístico e que oferece somente condições mínimas de apoio à visitação e gestão, é de fundamental importância que as estruturas físicas sejam de fato implantadas. Desta forma, seria possível melhorar a qualidade da visitação no Parque, minimizar os impactos negativos que atualmente são perceptíveis e, ainda, contribuir para o desenvolvimento do turismo em Diamantina e região.

\section{Contribuições do PEBI Para o Desenvolvimento Socioeconômico e Turístico de Diamantina}

A análise acerca da contribuição do Parque Estadual do Biribiri para o desenvolvimento socioeconômico e turístico de Diamantina revelou que o PEBI, atualmente, contribui mais para a atividade turística do que para o desenvolvimento socioeconômico. Um dos fatores que levam a essa percepção é a falta de estruturação da Unidade de Conservação.

A classificação do Parque como Unidade de Proteção Integral provoca muitos problemas para as comunidades do entorno. Estes problemas decorrem do fato de que muitas atividades tradicionalmente desenvolvidas por elas como fonte de renda foram proibidas, como o garimpo, a coleta de sempre-viva, a caça e a retirada de lenha. Com a proibição destas atividades, nenhuma outra forma de renda alternativa foi viabilizada a esta comunidade. Assim, a estruturação do Parque se faz necessária, 
também, como uma forma de compensar as comunidades do entorno, possibilitando uma nova alternativa de renda, por meio desenvolvimento do turismo.

O Parque Estadual do Biribiri, também poderia contribuir de maneira mais incisiva para o desenvolvimento econômico do município, por meio do aumento e de um melhor aproveitamento do Imposto Sobre Circulação de Mercadorias e Prestação de Serviços - ICMS Ecológico, que de acordo com o site ICMS Ecológico (2012), pode ser entendido como:

[...] um instrumento de estímulo à conservação da biodiversidade, quando ele compensa o município pelas Áreas Protegidas já existentes e também quando incentiva a criação de novas áreas Protegidas, já que considera o percentual que os municípios possuem de áreas de conservação em seus territórios.

O ICMS Ecológico exerce um importante papel para o desenvolvimento socioeconômico dos municípios, pois é uma maneira de incentivar a conservação de áreas com características naturais relevantes e de compensar o município pelas Áreas Protegidas existentes, por meio de retorno financeiro.

Em uma visão geral, observa-se que o PEBI é um importante atrativo para Diamantina e que poderia, se bem estruturado, gerar mais retorno socioeconômico para a região, visto seu amplo potencial face a sua realidade atual.

\section{Avaliação das Propostas do Plano de Manejo do PEBI}

Foram realizadas avaliações acerca da viabilidade da construção das estruturas presentes no Plano de Manejo do PEBI, assim como a adequação das mesmas à realidade do Parque. As avaliações apresentadas tiveram por base as entrevistas realizadas, bem como o conhecimento e a opinião dos autores sobre o assunto.

A seguir, serão abordadas todas as estruturas presentes na proposta do Plano de Manejo, acompanhadas das considerações acerca de sua implantação.

A proposta de implantação do Centro Administrativo $\left(150 \mathrm{~m}^{2}\right.$, localizado na Zona de Uso Especial, porção Sul) é viável e relevante, sendo essa uma estrutura necessária, por ser um espaço destinado para a organização do uso público do Parque e que auxiliaria na gestão da Unidade de Conservação.

Outra estrutura proposta é o Centro de Manutenção e Apoio ao Funcionário (300 m², localizado na Zona de Uso Especial, porção Sul) que foi considerada importante, pois auxilia nas atividades dos funcionários do Parque.

Já a presença da Casa do Funcionário (96 m², localizada na Zona de Uso Intensivo, porção Sul), foi considerada desnecessária, pois não abrange a totalidade da composição do quadro de funcionários previsto pelo Plano de Manejo da Unidade de 
Conservação e, também, tendo em vista a proximidade do Parque à cidade de Diamantina. Outro aspecto de interesse público para a não implantação desse espaço na área do Parque é a economia de recursos que seriam investidos para tal fim.

O Centro de Visitantes $\left(280 \mathrm{~m}^{2}\right.$, localizado na Zona de Uso Intensivo, porção Sul), é uma estrutura fundamental, tendo em vista um dos objetivos do Parque, que é a visitação pública, pois seria um espaço para informação ao visitante e sensibilização acerca da importância desse patrimônio natural. É necessário fazer uma revisão dessa proposta, considerando os resultados de pesquisas de demanda realizadas nos últimos anos, que revelam um alto índice de visitação no Parque Estadual do Biribiri. Outra possibilidade é a elaboração do estudo de capacidade de carga do espaço, indispensável para a melhor administração da área. De acordo com a Organização Mundial do Turismo (2003 apud SIMIQUELI et al.), capacidade de carga:

[...] refere-se à capacidade de desenvolvimento e de utilização pelo visitante que pode ser atingida sem resultar em danos ao meio ambiente físico (natural e artificial) e na geração de problemas socioculturais e econômicos à comunidade local, garantindo, ainda, benefícios à comunidade e manutenção de um equilíbrio adequado entre o desenvolvimento e a conservação.

Outra proposta analisada foi a implementação da Portaria Principal $\left(20 \mathrm{~m}^{2}\right.$, localizada na Zona de Uso Intensivo, porção Sul), estrutura fundamental para a organização e controle das atividades realizadas no Parque e para controle de sua capacidade de carga.

O Núcleo de Apoio ao Uso Público com Primeiros Socorros $\left(150 \mathrm{~m}^{2}\right.$, localizado na Zona de Uso Intensivo, na Cachoeira da Sentinela), é uma estrutura necessária, visto o alto fluxo de visitação nos atrativos localizados nessa área do Parque e a frequente ocorrência de acidentes. Esse seria, então, um ponto de apoio emergencial, onde o visitante seria respaldado com os primeiros socorros, sendo preparado para possíveis atendimentos mais complexos, que seriam realizados na área urbana de Diamantina.

A construção de um estacionamento na Cachoeira da Sentinela, localizado na Zona de Uso Intensivo, é fundamental, pois minimizaria os roubos e furtos que acontecem frequentemente devido à falta de vigilância e fiscalização nesta área. Sendo assim, este espaço contribuiria para o aumento da segurança e conforto dos visitantes do PEBI.

Em relação à implementação da Guarita na Estrada Municipal Sentido Pinheiros -Diamantina (9 $\mathrm{m}^{2}$, localizada na Zona de Uso Especial), observa-se que esta estrutura é de grande importância para o Parque, pois seria adotado mais um ponto de controle, de forma a assegurar o monitoramento da área visando a preservação do ambiente local. 
Quanto à construção de uma Guarita na Vila do Biribiri $\left(9 \mathrm{~m}^{2}\right.$, localizada na Zona de Uso Especial), observa-se que tal estrutura causaria grande impacto visual no ambiente. Além disso, a implantação de qualquer estrutura dentro da Vila do Biribiri se trata de investimentos do poder público em uma área privada, o que torna tais ações inviáveis.

A implantação de um Centro de Referência do Parque (casa na Vila do Biribiri) também é uma questão que deve ser avaliada de forma minuciosa, pois envolve a ocupação de uma área privada que estaria se beneficiando de recursos advindos do poder público. Devem ser feitas novas análises e propostas relacionadas a essa problemática, considerando a realidade do Parque Estadual do Biribiri, que não possui a Vila inserida no seu espaço interno.

Já a implantação da Guarita Sentinela $\left(9 \mathrm{~m}^{2}\right.$, localizada na Zona de Uso Intensivo), é dispensável, em função da presença de outras estruturas de controle de uso público nesta área do Parque.

Outra proposta do Plano de Manejo é a construção da Portaria Mendanha (40 $\mathrm{m}^{2}$, localizada na Zona de Uso Especial, no distrito de Mendanha), estrutura importante, tendo em vista a possibilidade de acesso e controle do Parque por meio dessa região. Além disso, a abertura dessa portaria poderia contribuir para a geração de renda e para o desenvolvimento do turismo neste distrito de Diamantina.

A instalação de uma Base de Apoio ao Pesquisador foi considerada essencial, visto que o Parque Estadual do Biribiri recebe muitos pesquisadores. No Plano de Manejo consta que a localização dessa estrutura será definida após a regularização fundiária, utilizando- se uma das construções já presentes no Parque. Ressalta-se a viabilidade de utilização de uma das casas que serão desapropriadas, reduzindo a construção de novas estruturas e os gastos públicos. Essa seria, também, uma possibilidade de ter mais de uma Base de Apoio ao Pesquisador, em pontos diferentes, visto que são várias casas a serem desapropriadas.

Também está previsto no Plano de Manejo a implantação de sanitários e estacionamento próximo à Fazenda Duas Pontes, localizado na Zona de Uso Intensivo. A construção dessa estrutura foi considerada importante, porém, inviável, pois permitiria a entrada de pessoas sem pagamento de taxa de visitação.

A última proposta do Plano de Manejo no que se refere à implantação de estruturas físicas de apoio à visitação e gestão do Parque, foi em relação à presença do Portão na entrada pela Fazenda Duas Pontes, localizado na Zona de Uso Intensivo. As considerações acerca dessa estrutura foram semelhantes às realizadas na avaliação anterior. Tanto a proposta de sanitários e estacionamentos próximos a Fazenda Duas Pontes, quanto ao portão neste mesmo local fazem-se necessários mediante a presença de uma portaria para controle de acesso à área, a cobrança de taxa de visitação, orientação sobre postura do visitante e administração dessas estruturas. Ressalta-se a necessidade da presença permanente de funcionários na área, ou estas instalações tornam-se desnecessárias e inviáveis. 


\section{As consequências da presença das estruturas propostas no Plano de Manejo do PEBI}

Também são passíveis de discussão quais as possíveis consequências da presença das estruturas previstas no Plano de Manejo para o Parque, para o turista, para a comunidade e para a região.

É nítido que a presença de tais estruturas poderia contribuir de maneira positiva, pois possibilitaria um maior controle da área do Parque, aumento da conservação do ambiente, além de melhoria da qualidade da visitação pública.

A presença das estruturas propostas pelo Plano de Manejo é fundamental para o apoio a visitação e gestão do Parque, visto que tais estruturas possibilitariam um melhor ordenamento e utilização do espaço do PEBI, destinando locais adequados para determinados tipos de atividades, implicando na conservação do ambiente, além do incentivo a práticas ecologicamente corretas, por meio de ações de educação ambiental desenvolvidas nesses espaços.

Outro importante aspecto positivo advindo da estruturação do PEBI seria o envolvimento da comunidade com as atividades do Parque, representando possibilidades de geração de emprego e renda e oportunidades de lazer para a comunidade e turistas.

Para os visitantes, as estruturas propostas pelo Plano de Manejo da UC atuariam de forma positiva, visto que influenciariam na qualidade da visitação ao proporcionarem maior segurança e conforto, além de oferecerem mais informações sobre o PEBl. Além disso, tais estruturas poderiam minimizar alguns dos atuais problemas vivenciados pelos visitantes, como a ocorrência de roubos e furtos; a falta de locais destinados à higiene pessoal e para disposição de lixo; a falta de informação sobre o Parque, sobre seus atrativos e sobre o comportamento adequado do visitante; assim como a falta de base para prestação de primeiros socorros, em caso de emergências.

Já no que se refere à comunidade local, as consequências da presença de estruturas físicas na área do PEBI seriam também positivas. A estruturação do Parque pode possibilitar maior envolvimento da comunidade local, que passaria a participar de forma mais ativa deste processo e a perceber as possibilidades de benefícios gerados por meio da criação e implantação do Parque. Estes benefícios podem ser a geração de emprego e renda, a valorização do espaço e a preocupação em se configurarem como parceiros no processo de preservação da Unidade de Conservação.

Outra possibilidade advinda da estruturação do Parque Estadual do Biribiri seria incrementar a imagem de Diamantina como um destino de turismo ecológico, o que hoje é apresentado como um grande potencial para a cidade, mas que ainda é incipiente. Assim, sendo bem estruturado, o PEBI poderia se tornar, também, um dos principais atrativos ecoturístico da região.

A implantação de estruturas físicas pode contribuir, ainda, para a diminuição considerável de alguns dos impactos negativos atualmente encontrados no Parque 
Estadual do Biribiri, visto que a presença dessas estruturas possibilita a organização da atividade turística e a orientação dos visitantes, influenciando o comportamento destes no Parque. Além disso, se construídas em locais apropriados, permitiriam que os visitantes realizassem suas necessidades, como alimentação, hospedagem e higiene de forma adequada e em locais que causariam menor impacto, proporcionando maior conservação ambiental.

Por fim, a presença de estruturas físicas de apoio à visitação e gestão do PEBI, propostas pelo Plano de Manejo, implicariam, então, em consequências positivas para toda a sociedade e o meio ambiente nos quais o Parque exerce influência. Se essas propostas forem revistas e adequadas à atual realidade do Parque, os benefícios possivelmente seriam ainda maiores.

\section{Conclusões}

O presente trabalho foi realizado na tentativa de explorar as possibilidades de desenvolvimento do Parque Estadual do Biribiri e da região na qual ele está inserido, a partir da análise acerca da viabilidade da implantação das estruturas físicas de apoio à visitação e gestão, previstas no Plano de Manejo, tendo em vista as opiniões dos agentes entrevistados e dos autores desta pesquisa.

Os resultados do estudo apontaram que tais estruturas são fundamentais para o cumprimento dos objetivos do Parque como uma Unidade de Conservação de Proteção Integral. No entanto, a UC, atualmente, não está apta a receber esse tipo de investimento, devido à falta de regularização fundiária de seu espaço, fato que é dependente de políticas públicas específicas. Este problema deve ser resolvido o quanto antes para que, dessa forma, as ações dentro do PEBI possam ser desenvolvidas e efetivadas.

Foi identificado pela pesquisa que a proposta do Plano de Manejo no que se refere a estruturas de apoio à visitação e gestão do Parque Estadual do Biribiri é de fundamental importância e se adéqua as necessidades do Parque. Porém, para que possa ser implementado com sucesso, este documento deve, antes, passar por uma revisão e atualização minuciosa. De acordo com Alves (1996), o Plano de Manejo é um documento que deve ser atualizado a cada cinco (05) anos.

Esta atualização deve contar com a participação da comunidade, de profissionais atuantes no Parque e entorno, e também de pesquisadores com conhecimento na área. Também é fundamental que seja elaborado o estudo de capacidade de carga anteriormente à implantação de qualquer estrutura na Unidade de Conservação, visando adequar tais construções ao número de visitantes que o Parque irá receber. Segundo Ruschmann (2010, p.113), 
[...] é preciso identificar o conceito de capacidade de carga para o planejamento do turismo, considerando que se trata de uma noção que reconhece que tanto os recursos naturais como os construídos pelo homem têm um limite para absorver visitantes; esse limite, quando ultrapassado, provoca sua deterioração.

Ainda foi possível perceber que a presença das estruturas físicas propostas pelo Plano de Manejo é imprescindível, tendo em vista que o Parque Estadual do Biribiri recebe um número alto de visitantes durante todo o ano, e que a visitação à Unidade de Conservação necessita de uma maior organização e controle. Ainda neste aspecto, é importante ressaltar que para o efetivo funcionamento das estruturas, se faz necessário um corpo de profissionais contratados e capacitados para atender as necessidades eminentes da sua visitação e gestão.

A existência das estruturas é de grande importância para o desenvolvimento do turismo, sendo este uma possibilidade de geração de emprego e renda para a comunidade e, podendo, ainda, atuar como agente de minimização dos impactos causados pelo desenvolvimento desordenado da atividade. Segundo a União Internacional para a Conservação da Natureza (IUCN) (apud KINKER, 2005, p.21) o ecoturismo como viagens a áreas preservadas, promove "a conservação, com mínimo impacto, e propicia o desenvolvimento socioeconômico das comunidades locais".

Concretizar as propostas previstas no Plano de Manejo do Parque Estadual do Biribiri devidamente atualizadas é um passo importante para o desenvolvimento ambiental, socioeconômico e turístico de Diamantina e região, visto que o Parque é um atrativo natural singular e que hoje não é utilizado de forma organizada e sustentável, impedindo a ampliação de benefícios para todos os atores envolvidos.

Por fim, vale lembrar que, segundo Rushmann (2010), é preciso haver equilíbrio entre turismo e meio ambiente, de forma a assegurar que a atratividade dos recursos naturais não seja a causa de sua degradação. Dessa forma, trabalhar ações sustentáveis no Parque Estadual do Biribiri, considerando o disposto no seu Plano de Manejo, é de fundamental importância para o desenvolvimento ecoturístico da região e se constitui em uma alternativa para harmonizar o turismo com o meio ambiente.

\section{Referências bibliográficas}

ALVES, K.R. Uma Visão Geral das Unidades de Conservação no Brasil. In. RAMOS A.; CAPOBIANCO, J.P. Unidades de Conservação no Brasil: aspectos gerais, experiências inovadoras e a nova legislação (SNUC). Documentos do ISA. no 01.1996. 
ÁVILA, G.C.; PAULA. V.C. Relatório de Atividades Realizadas: Parque Estadual do Biribiri. Instituto Estadual de Florestas. Diamantina, 2010. 105p.

BRASIL. Lei $\mathbf{n}^{\circ}$ 9985, de 18 de julho de 2000. Regulamenta o art. 225, § 10, incisos I, II, III e VII da Constituição Federal, institui o Sistema Nacional de Unidades de Conservação da Natureza e dá outras providências. Brasília. MMA/SBF, 2000.

DENCKER, A.F.M. Métodos e Técnicas de Pesquisa em Turismo. São Paulo: Futura, $3^{\circ}$ Ed., 1998. 287 p.

DENCKER, A.F.M. Pesquisa em Turismo: planejamento, métodos e técnicas. São Paulo: Futura, 2007. 355 p.

IEF - Instituto Estadual de Florestas. Parque Estadual do Biribiri. Disponível em $<$ http://www.ief.mg.gov.br/areas-protegidas/200?task=view>. Acesso em: 3 de ago. de 2011.

MINISTÉRIO DO TURISMO. Ecoturismo: orientações básicas. 2.ed. Brasília, 2010. 90 p.

NEIMAN, Z.; RABINOVICI, A. (org.).Turismo e Meio Ambiente no Brasil. 1ed. Barueri, SP. Editora Manole, 2010.

RUSCHMANN, D. van de M. Turismo e Planejamento Sustentável: a proteção do meio ambiente. 16.ed.. Campinas: Papirus, 2010. 192 p. (Coleção turismo).

SILVEIRA, C.E; MEDAGLIA, J. Relatório Final de Pesquisa: Perfil da Demanda Turística Real de Diamantina e Região. Projeto de Pesquisa do Curso de Turismo da UFVJM. Diamantina, 2011.

SIMIQUELI, R.; FONTOURA, L.M.; ROCHA, C.H.B. Planejamento Ambiental em Trilhas: Capacidade de Carga Antrópica, Abordagens e Metodologias. Disponível em: <http://pt.scribd.com/doc/11566703/PLANEJAMENTO-AMBIENTAL-EMTRILHAS-CAPACIDADE-DE-CARGA-ANTROPICA-ABORDAGENS-EMETODOLOGIAS->. Acesso em: 14 nov. 2011.

STCP ENGENHARIA DE PROJETOS LTDA. Plano de Manejo do Parque Estadual do Biribiri, Secretaria de Estado de Meio Ambiente e Desenvolvimento Sustentável - Semad; Instituto Estadual de Florestas - IEF, Vol.1, Curitiba, 2004.

\section{Nota:}

${ }^{1}$ Texto adaptado de Trabalho de Conclusão de Curso (Graduação em Turismo) da Universidade Federal dos Vales do Jequitinhonha e Mucuri. 
Raquel Campos Antunes: Universidade Federal dos Vales do Jequitinhonha e Mucuri, Diamantina, MG, Brasil.

Email: raquel_campos_@hotmail.com

Link para o currículo Lattes: http://lattes.cnpq.br/4596254741783627

Álvaro José Ferreira Tôrres: Universidade Federal dos Vales do Jequitinhonha e Mucuri, Diamantina, MG, Brasil.

Email: alvaro torres0811@hotmail.com

Link para o currículo Lattes: http://lattes.cnpq.br/0613523386091311

Raquel Faria Scalco: Universidade Federal dos Vales do Jequitinhonha e Mucuri, Diamantina, MG, Brasil.

Email: raquel.scalco@yahoo.com.br

Link para o currículo Lattes: http://lattes.cnpq.br/1858387591943845

Data de submissão: 28 de fevereiro de 2012

Data de recebimento de correções: 27 de abril de 2012

Data do aceite: 02 de maio de 2012

Avaliado anonimamente 